\title{
Hubungan Sebaran Kerang Totok Geloina sp. (Bivalvia: Corbiculidae) dengan Vegatasi Mangrove di Ujung Alang Segara Anakan Cilacap Jawa Tengah
}

\author{
Chrisna Adhi Suryono \\ Departemen IImu Kelautan, Fakultas Perikanan dan IImu Kelautan, Universitas Diponegoro \\ JI. Prof. Soedarto, SH. Kampus UNDIP Tembalang, Semarang \\ Email: chrisna_as@yahoo.com
}

\begin{abstract}
Abstrack
Segera Anakan is the widest estuaries in Java Island and the famous high diversity. One of fauna found which associate with the mangroves was totok mussel Geloina sp. That mussel had economic value so that faced high exploited along season. Considering that condition a study of the correlation between Geolina distribution and the mangroves vegatiaon. The research was carried out at Ujung Alang areas in Segara Anakan Cilacap on different station which had different mangroves abbundancas. The case study type research and sampling area method was used to collect the data of information of the Geloina sp. The data collected in the field was mussel and mangroves population and water quality condition. The result of the study showed, Thad the Geloina sp was uniform distribute along the fourth station which had different diversity and numbers of mangrove. The class length of $6-6,9 \mathrm{~cm}$ was the highs number of mussel class on forth station in Ujung Alang Segara Anakan Cilacap
\end{abstract}

Keywords: Segara Anakan, Geloina sp, Mangrove

\begin{abstract}
Abstrak
Segara Anakan merupakan salah satu estuaria terbesar di Pulau Jawa yang terkenal dengan keanekaragaman hayatinya. Diantara biota yang terdapat adalah kerang totok (Geloina sp) yang berasosiasi dengan hutan mangrove. Karena memiliki nilai ekonomis maka menjadi target penangkapan. Maka dari itu sangat tepat jika mempelajiti hubungan antara sebaran kerang Totok Geloina terhadap vegetasi mangrove. Penelitian dilakukan di Ujung Alang Segara Anakan di Cilacap pada empat stasiun yang berbeda lokasinya. Sifat penelitian adalah studi kasus, metoda pengambilan sampel yang digunakan adalah metoda sampling area. Data yang diambil meliputi kerang, manrove dan kondisi perairan setempat. Hasil penelitian menunjukan kerang totok Geloina yang didapat tidak terpengaruh oleh vegetasi mangrove baik jenis maupun jumlah pohon. Populasi kerang terbanyak pada semua stasiun adalah kelas ukuran $6-6,9 \mathrm{~cm}$ di Ujung Alang Seagara Anakan Cilacap
\end{abstract}

Kata Kunci : Segara Anakan, Geloina sp, Mangrove

\section{PENDAHULUAN}

Hutan mangrove merupakan satu satunya penghubung antara daratan dan lautan di kawasan pesisir tropis dan subtropis, disamping itu memiliki peran yang sangat vital dalam menjaga habitat organisme-organisme pesisir dari gangguan alam (Alongi, 2008 \& Barbier et al, 2008). Ekosistem mangrove di Segrara Anakan dicirikan dengan tingginya keragaman fauna yang berasosiasi dengan ekosistem mangrorove seperti bivalvia (Suryono, 2012). Lebih kusus lagi kelompok kerang dari famili Corbiculidae yang berasosiasi dengan mangrove seperti Geloina erosa, Geloina expansa dan Geloina bengales (Morton, 1984) 
Penelitian sebelumya yang dilakukan di Segara Anakan menunjukan bahwa kerang Geloina menyebar merata pada setiap perairan yang baik yang berslinitas tinggi meupun rendah (Suryono, 2012). Segara Anakan merupakan salah satu estuaria yang tersisa di Pulau Jawa, biasanya dicirikan dengan sebaran yang merata pada organisme yang khas di daerah tersebut dan menunjukan keanekaragaman yang sangat rendah (Kenish, 1990 dan Odum 1993). Untuk membuktikan bahwa daeah estuaria yang berhutan mangrove seperti Segara Anakan sangat rendah keanekaragaman biota dasar perairan seperti kerang Geloina maka perlu dilakukan penelitian hubungan antara ekosistem dominan (mangrove) terdahadap kerang Geloina.

\section{MATERI DAN METODE}

Materi yang digunakan dalam penelitian ini adalah kerang Geloina dan Mangrove yang diambil dan diukur di daerah Ujung Alang Segara Anakan Cilacap dan beberapa parameter lingkunagn seperti Salinitas, Suhu, subtract dasar dan bahan organik. Penelitian ini menggunakan metode survei dan pengukuran populasi vegetasi mangrove menggunakan metode sampling Point Centered Quarter Method (PCQM) (Cottam \& Curtis, 1956 dalam Cintron \& Novelli, 1984). Identifikasi spesies mangrove berpedoman pada
Tomlinson (1986), Kitamura, at al (1997) dan Wang at al (2003). Dalam penelitian ini dipilih 4 stasiun penelitian dimuara Sunagai Ujung Alang. Pengambilan sampel kerang Geloina sama dengan lokasi pengukuran mangrove. Pengambilan sampel mengacu pada Irwani dan Suryono (2006) dan Suryono (2012) dimana dilakukabn dengan transek seluas $10 \mathrm{~m}^{2}$ dan penghitungan sampel dilakukan dengan quadrant $1 \mathrm{~m}^{2}$ dan diambil pada 10 titik yang berbeda dan diulang 3 kali pada waktu berbeda. Penentuan letak quadran pada areal transek seluas $10 \mathrm{~m}^{2}$ terlebih dahulu ditentukan diatas kertas sebelum terjun mengambil sampel hal ini dilakukan untuk menghindari human bias akibat subjektifitas peneliti.

\section{HASIL DAN PEMBAHASAN}

Hasil pengamatan terhadap vegetasi mangrove di lokasi penelitian ditemukan 10 jenis mangrove yang menyusun populasi ekositem mangrove di daerah Ujung Alang Segara Anakan Cilacap. Jenis jenis mangrove tersebut adalah Avecinia marina, A. alba, Soneratia caseolaris, S. alba, Rhizophora apiculata, R. mucronata, Bruguiera cylindrical, B. gymnorhiza, Aegiceras corniculatum dan Nypa fruticans. Vegetasi mangrove yang ditemukan lebih jelasnya dapat di lihat dalam Tabel 1.

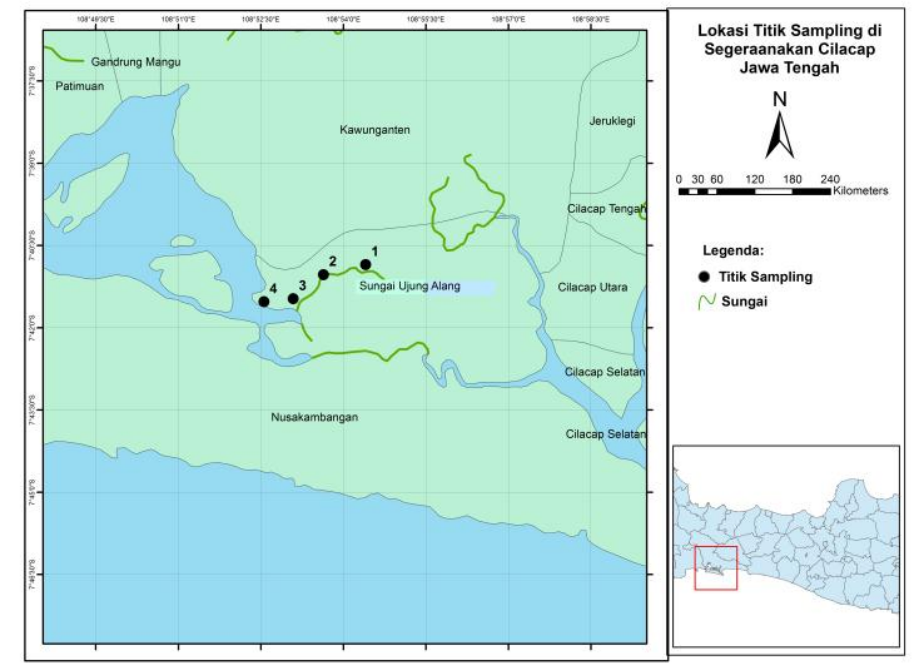

Gambar 1. Peta loakasi penelitian dan titik sampling di Ujung Alang Segara Anakan Cilacap Jawa Tengah 
Tabel 1. Jensis jenis vegetasi mangrove yang ditetemukan di Ujung Alang Segara Anakan Cilacap Jawa Tengah

\begin{tabular}{|c|c|c|c|c|c|}
\hline \multirow{2}{*}{ No } & \multirow{2}{*}{ Jenis } & \multicolumn{4}{|c|}{ Stasiun } \\
\hline & & 1 & $\|$ & III & IV \\
\hline 1 & Avicenia marina & + & + & + & + \\
\hline 2 & Avicenia alba & + & + & + & + \\
\hline 3 & Soneratia caseolaris & + & + & + & + \\
\hline 4 & Soneratia alba & - & - & + & + \\
\hline 5 & Rhizophora apiculata & + & + & + & + \\
\hline 6 & Rhizophora mucronata & + & + & + & - \\
\hline 7 & Bruguiera gymnorrhiza & - & - & + & + \\
\hline 8 & Bruguiera cylindrical & - & + & + & - \\
\hline 9 & Aegiceras corniculatum & + & + & + & + \\
\hline 10 & Nypa fruticans & + & + & + & + \\
\hline
\end{tabular}

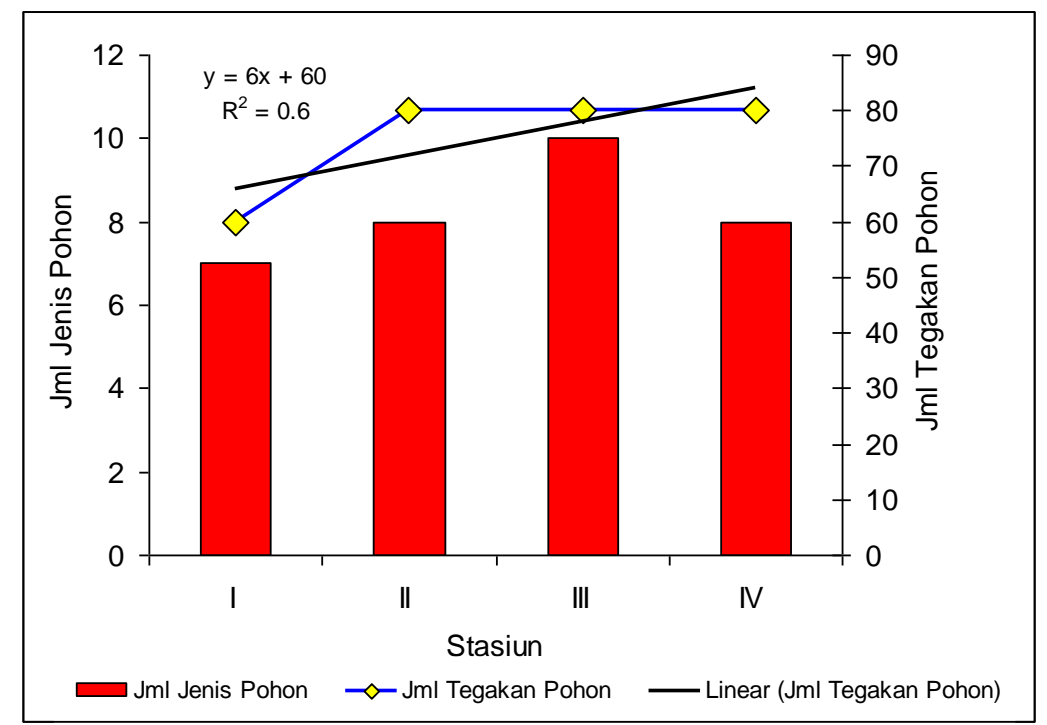

Gambar 2. Jumlah jenis pohon dan tegakan pohon mangrove yang ditemukan di Ujung Alang Segara Anakan Cilacap Jawa Tengah

Jenis jenis mangrove yang ditemukan di daerah Ujunng Alang Segara Anakan dapat dikatakan menyebar merata di seluh stasiun pengamatan. Jumlah terbanyak ditemukan dalam stasiun III dimana kesepuluh tumbuhan mangrove di temukan sedangkan di stasiun I, II dan IV hanya di dapatkan antara $7-8$ jenis mangrove.

jumlah

Hubungan antara jumlah pohon dan kecenderungan positip dimana semakin besar jumlah jenis pohon akan diikuti oleh peningkatan jumlah tegakan pohon mangrove $(r=0.77)$.
Data yang diperoleh dari kerang Geloina menunjukan bahwa jumlah terbesar pada stasiun $\| I I=104$ ekor, $\|=95$ ekor, I = 91 ekor dan IV = 75 ekor. Jumlah terbesar pada kerang dengan ukuran 6 $6,9 \mathrm{~cm}$ tersebar dan mendominansi pada setiap stasiun.

Gambar 4 Menunjukan bahwa sebaran jumlah kerang Geloina di daerah Ujung Alang tidak mengikuti sebaran jumlah jenis dan sebaran jumlah pohan mangrove pada setiap stasiun hal tersebut juga dibuktikan dengan regresi seperti terlihat pada gambar 5 


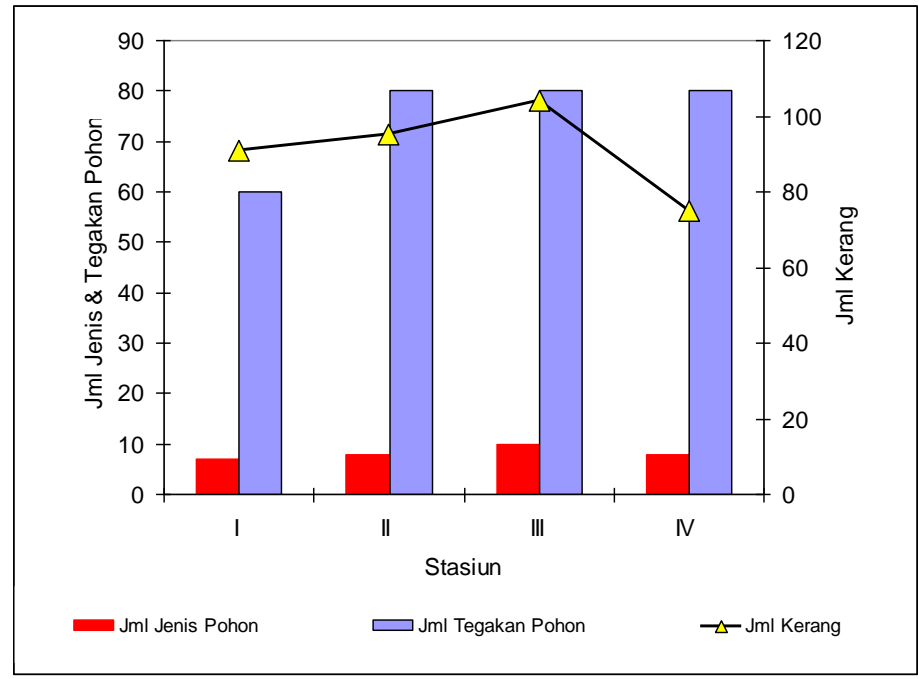

Gambar 3. Jumlah individu dan kelas panjang $(\mathrm{cm})$ kerang Geloina yang ditemukan di Ujung Alang Segara Anakan Cilacap Jawa Tengah

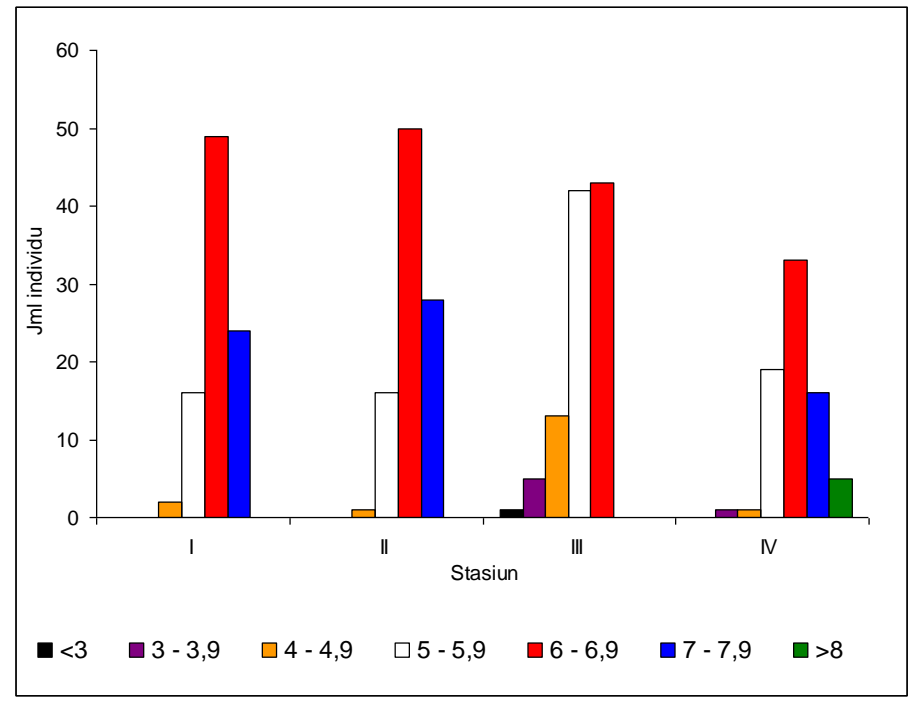

Gambar 4. Jumlah jenis dan jumlah tegakan pohon mangrove terhadap jumlah kerang Geloina yang ditemukan di Ujung Alang Segara Anakan Cilacap Jawa Tengah
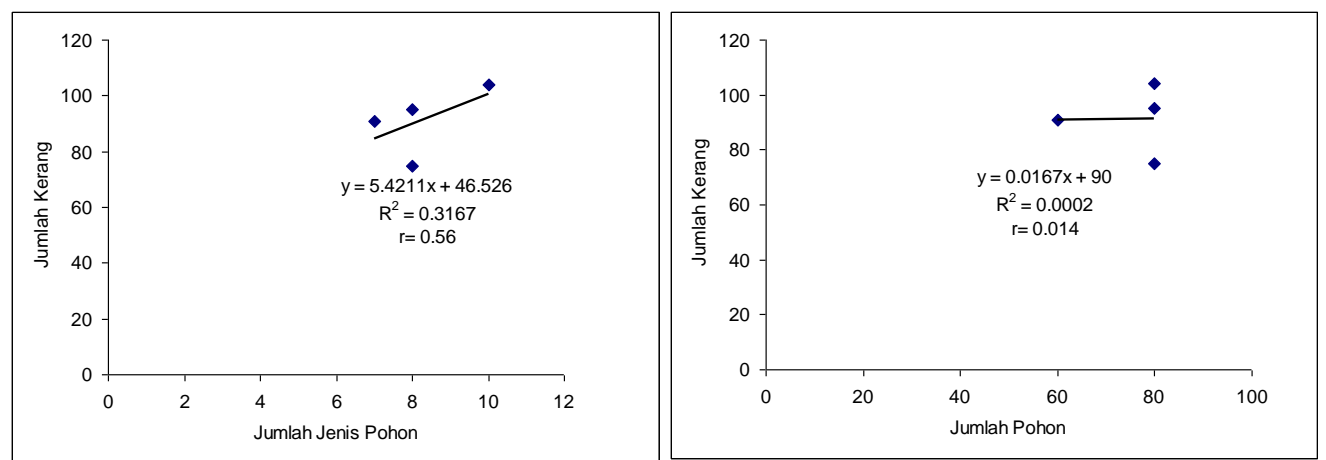

Gambar 5. Hubungan regresi antara jumlah kerang dengan jumlah jenis pohon dan jumlah kerang dengan jumlah pohon mangrove di Ujung Alang Segara Anakan Cilacap Jawa Tengah 
Hasil uji regresi menunjukan kurang eratnya hubungan antara jumalah kerang dan jumlah jenis pohon maupun jumlah pohon mangrove terbukti dari nilai $r<0,6$. Hal tersebut menunjukan banyak sedikitnya kerang Geloina yang terdapat di daerah Ujung Alang tidak kurang dipengaruhi oleh banyak sedikitnya jenis maupun jumlah pohon mangrove yang ada.

Bila dilihat dari gambar 4 dan table 2 terlihat bahwa jumah kerang Geloina terbesar terdapat pada stasiun II (95 ekor) dan III (104 ekor) dengan salinitas pada stasiun tersebut II (15 ppt) dan III (30 ppt). Dilihat dari data tersebut terlhat bahwa sebaran terbanyak kerang Geloina cenderung pada daerah estuaria, namun bila jumlah kerang Geloina diregresekan dengan salinitas menunjukan tidak adanya hubungan keeratan diantara dua fariabel tersebut $r=0,23$ seperti yang terlihat pada gambar 6 .
Penyebaran kerang Geloina di Ujung Alang Segara Anakan terlihat merata tidak terpengaruh oleh banyak sedikitnya jenis pohon maupun jumlah pohon. Demikian juga terhadap salinitas yang bersalinitas tinggi maupun rendah. Hal tersebut sesuai dengan Odum (1993) yang menyatakan bahwa penyebaran merata datap terjadi jika persaingan antar individu sangat keras yang mendorong pembagian ruang hampir sama. Kennish (1990) mengatakan bahhwa keanekaragaman di daerah estuaria biasanya rendah tetapi kepadatan organismennya yang ada bisa sangat tinggi. Kepadatan organisme yang tinggi baik antara spesies maupun sesame spesies itu sendiri menyebabkan adanya persaingan untuk mendapatkan ruang guna memeperoleh makanan, tempat berlindung dari predator dan tempat untuk berkembang biak. Dengan demikian Geloina sebagai organisme bentik

Tabel 2. Kondisi linkungan masing masing stasiun penelitian di Ujung Alang Segaea Anakan Cilacap Jawa Tengah

\begin{tabular}{|c|c|c|c|c|c|}
\hline Stasiun & Suhu ( $\left.{ }^{\circ} \mathrm{C}\right)$ & $\begin{array}{c}\text { Salinitas } \\
(\mathrm{ppt})\end{array}$ & Subtrat & $\begin{array}{c}\text { Bahan } \\
\text { Organik (\%) }\end{array}$ & Genangan \\
\hline I & 29 & 13 & Lumpur berpasir & 16,15 & Terendam saat pasang \\
II & 29 & 15 & Lumpur berpasir & 16,44 & Terendam terus \\
III & 28 & 30 & Lumpur berpasir & 15,27 & Terendam terus \\
IV & 28 & 32 & Lumpur berpasir & 14,90 & Terendam terus \\
\hline
\end{tabular}

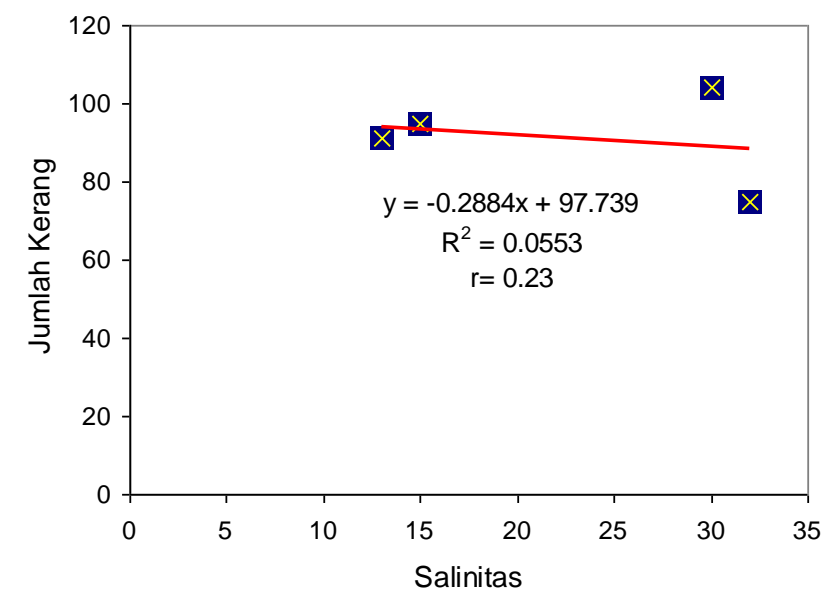

Gambar 6. Hubungan regresi antara jumlah kerang dengan Salinitas di Ujung Alang Segara Anakan Cilacap Jawa Tengah 
harus bersaing dengan organisme bentik lainnya yang hidup di daerah mangrove seperti dari golongan Polychaetha dan Crustacea (Kennish, 1990). Barnes dan Hughes (1988) menjelaskan bahwa predasi bukan merupakan salah satu faktor yang mengontrol kepadatan organisme bentik tetapi kepadatan organisme menthik lebih banyak dipengaruhi oleh kompetisi. Lebih lanjut Barnes dan Hughes (1988) menjelaskan bahwa kompetisi merupakan faktor untuk mempertahankan ekspansi yang terbatas, meskipun faktor fisik dan biologis dalam lingkungan dketahui berpengaruh langsung dan dapat menyebabkan berkurangnya jumlah individu dalam populasi. Jlka melihat kondisi lingkungan selama penelitian pada ke empat stasiun pengamatan yang berbeda salinitasnya menunjukan perbedaan namun suhu, bahan organik mau pun vegetasi hampir sama sehingga dapat dikatakan bahwa daerah tersebut tidak memiliki perbedan yang ekstrim yang dapat menyebabkan organisme akan berbeda dalam jumlah karena penyesuaan terhadap lingkungannya.

Dari data yang ada pada hasil penelitian menunjukan bahwa pada daerah yang bersalinitas 15 - 30 ppt (stasiun II dan III) rata rata kepadatanya lebih tinggi dari pada stasiun I (13 ppt) dan stasiun IV (32 ppt) yang sasinitasinya lebih rendah dan lebih tinggi. Penurunan jumlah individu pada daerah bersalinitas rendah dan tinggi (stasiun I dan IV) diperkirakan karena pengaruh pengambilan oleh nelayan karena bila dilihat dari kondisi lingkungan dapat dikatakan keempatnya memiliki kondisi lingkungan yang relative sama. Dijumpainya Geloina dengan ukuran panjang cangkang yang bervariasi disemua stasiun hal tersebut diduga karena hampir seragamnya tipe subtrat dan bahan organik yang ada daerah tersebut. Subtrat Lumpur berpasir merupakan subtrat yang mendominansi di daerah Segaraanakan (Suryono, 2012). Di duga sutrtat jenis inilah yang cocok sebagai habitat kerang Geloinaa. Sumber makan juga tersedia di daerah ini karena hampir sebagian besar wilayah estuaria Segaraanakan bervegetasi mangrove yang merupakan sumber bahan organik dari hasil decomposisi daun mangrove Suryono (2006). Hal yang sama juga ditemukan oleh Ewusie (1990) di sepanjang pantai Malaysia, dimana pada bagian tepi didominasi oleh Avicenia dan Sonneratia. Natalia (1999) juga menemukan jenis tumbuhan yang mendoninasi adalah Avicenia dan Sonneratia pada penelitianya, dimana subtratnya berupa lumpur hasil sedimentasi, hal ini sangat persis dengan yang ada di Segara Anakan sekarang ini. Friess, et al, (2011) mengemukakan bahwa mangrove dapat ditemukan pada daerah yang perubahan lingkungannya sangat besar seperti adanya akresi dan erosi dan mangrove akan selalu ada pada daerah yang berbeda secara fisik dan geomorfologis. Oleh kerena itu kondisi yang mendukung untuk tumbuh dan kembangya kerang Geloina di Segara Anakan diduga karena habitat yang sesuai seperti subtrat dasar, bahan organik sebagai bahan makanan, salinitas yang payau, adanya pohon maangrove yang relatip lebat. Karana sesuai tersebut maka diduga pada daerah tersebut terdapat kerang dari berbagai ukuran, karena pada daerah yang bersalinitas lebih tinggi spat banyak hidup di daerah tersebut. Hartati dan Suryono (2000) menyebutkan bahwa bivalvia dari golongan tiram yang menempel pada subtrat di estuaria Mlonggo Jepara mencapai puncaknya pada akhir musim hujan yang salinitasnya mulai naik.

Hal tersebut juga terlihat di Segaraanakan untuk kerang $G$. erosa dimana pada daerah yang salinitasnya tinggi terdapat banyak variasi kelas ukuran kerang. Bayne (1976) menginformasikan bahwa kerang yang hidup di daerah empat musim tumbuh dengan cepat pada musim semi dan panas dimana suhu dan salitas perairan meningkat dmikian juga terhadapt $G$. erosa yang yang hidup di Segar Anakan pada salinitas tinggi dan lebih tinggi akan memiliki ukuran dan variasi ukuran lebih besar hal ini membuktikan bahwa pada daerah yang bersalinitas tinggi cocok untuk hidup $G$. erosa hal tersebut terlihat dari ukuran variasi ukuran yang lebih besar 
dari pada daerah yang bersalinitas rendah. Tidak dijunpainya $G$. erosa dengan ukuran lebih kecil dari $2 \mathrm{~cm}$ di daerah penelitian mengindikasikan bahwa dimungkinkan individu muda kerang ini masih berada di bagian lain di hutan mangrove tersebut. Morton (1984) menyebutkan bahwa hal yang menarik dari struktur populasi $G$. erosa dan $G$. expansa adalah bahwa kedua spesies ini relative jarang ditemukan pada stadium mudanya dengan ukuran cangkang yang masih kecil. Banyaknya Geloina ditemukan didaerah mangrove dari pada jenis bivalvia lain diduga hanya jenis Geloina yang mampu beradaptasi pada daerah mangrove karena tingginya fluktuasi salinitas demikian juga lokoasi penelitian Segara Anakan.

Berdasarkan kondisi umum daerah pengamatan diatas dapat diketahui bahwa daerah tersebut memang cocok untuk kehidupan $G$. erosa. Morton (1976) mengatakan bahwa kawasan hutan mangrove Asia Tenggara ditemukanan berbagai macam jenis bivalvia dimana $G$. erosa merupakan salah satu organisme yang tersebar luas dan biasanya ditemukan sepanjang sisi daratan hutan mangrove maupun didalam hutan mangrove itu sendiri. Habitat ditemukannya hutan $G$. erosa ini hanya tergenang saat terjadi pasang tinggi dan terjadinya banjir meskipun $G$. erosa dapat hidup pada daerah yang terekspos dalam waktu yang lama (Morto, 1976). Subtrat di daerah penelitian di semua stasiun sebagian besar adalah lumpur berpasir. Demikian pula pada G. erosa di Singapura diketahui subtrarnya dasarnya adalah pasir kwarsa. Dapat dimengerti bahwa habitat kerang tersebut adalah pasir yang mengandung lumpur seperti yang ada di Segara Anakan maupun tempat tempat lain.

\section{KESIMPULAN}

Berdasar hasil penelitian dapat disimpulkan bahwa sebaran kerang Geloina di Ujung Alang Segara Anakan tidak tergantung dari banyaknya jenis tumbuhan mangrove maupun jumlah tegakan mangrove yang ada.

\section{DAFTAR PUSTAKA}

Alongi, D. M. 2008., Mangrove forests: resilience, protection from tsunamis, and responses to global climate change. Estuar Coast Shelf Sci 76:1-13

Barbier, E. B, Koch. E. W, and Silliman, B. R. 2008,. Coastal ecosystembased management with nonlinear ecological functions and values. Science 319:321-323

Bayne, B.L. 1976. Marine mussels: Their ecology and physiology. Cambridge University Press. Cambridge. $351 \mathrm{p}$

Cintron, $G$ and Novelli, Y. C., 1984. Methods for studying mangrove structure in Snedakar, S. C and Snedaker, C. G. The Mangrove ecosystem research method. UNESCO. United Kingdom. pp: 91 113.

Ewusie, J.Y. 1990. Elements of tropical ecology. Edisi Bahasa Indonesia. Penerbit ITB. Bandung. $369 \mathrm{hlm}$.

Friess, D.A., Krauss, K.W and, Horstman, E.M., 2011. Are all intertidal wetlands naturally created equal? Bottlenecks, thresholds and knowledge gaps to mangrove and saltmarsh ecosystems. Bul Rev doi.10.1111/j.1469-185x

Hartati, R dan Suryono. C.A. 2000. Oyster spatfall in Mlonggo Waters Jepara, Indonesia. Phuket marine Biology Center. Special Publication, 21(1): 183 $-186 \mathrm{pp}$.

Irwani dan Suryono, C.A. 2006., Struktur populasi dan distribusi kerang totok Geloina sp. (Bivalvia: Corbiculidae) di Segara Anakan Cilacap ditinjau dari aspek degradasi salinitas, IImu Kelautan 11(1):54-58

Kennish, M.J. 1990. Ecology of estuaries; Biological aspects. Vol II. CRC Press Inc. New York $391 \mathrm{p}$.

Kitamura, S., Anwar, C., Chaniago, A and Baba, S. 1997. Hanbook of mangroves in Indonesia; Bali and Lombok. JICA/ISME, Okinawa, $120 \mathrm{p}$.

Morton, B. 1976. The biology and functional of The Southeast Asian Mangrove Bivalve, Polymesoda Gelonia erosa (Solander, 1976). (Bivalve: Corbiculidae). Can. J. Zool. 54: 482 - 500 . 
Morton, B. 1984. A review of Polymesoda (Gelonia) Gray, 1842 (Bivalve: Corbiculidae) from Indo Pacific mangrove. Asian Mar. Biol. 1: 77- 86.

Natalia, F. 1999. Struktur hutan mangrove di kawasan hutan magrove Karang Anyar, Segara Anakan, Cilacap. J Kelautan Tropis I (3): 65 - 71.

Odum, E.P. 1993. Dasar dasar ekologi. Gajah Mada University Press. Yogyakarta. 693 hal.

Suryono. C.A. 2006. Struktur vegetasi mangrove di laguna Segara Anakana
Cilacap, Jawa Tengah. Ilmu Kelautan 11 (2):153- 157

Siuryono, C. A,. 2012,. Bioekologi kerang Totok Geloina sp, (Bivalvia: Corbiculidae) di Seagara Ananakan Cilacap Jawa Tengah. Buletin Oseanografi Marine 1 (5): 26-33.

Tomlinson, P.B. 1986. The botani of mangroves. Cambridges University Press. Cambridge. $383 \mathrm{p}$.

Wang, B.S., Liang, S.C., and Zhang WY., 2003. Mangrove flora of the world. Acta Bot Sin 45:644-653 